\title{
Equilocality and heterogeneity of constitutive heterochromatin: in situ localization of two families of highly repetitive DNA in Dociostaurus genei (Orthoptera)
}

\author{
E. RODRÍGUEZ IÑIGO, B. FERNÁNDEZ-CALVÍN†, J. CAPEL $\ddagger$ \& C. GARCÍA DE LA \\ VEGA* \\ Unidad de Genética, Departamento de Biología, Facultad de Ciencias, Universidad Autónoma de Madrid, 28049 \\ Madrid, †Unidad de Genética, Departamento de Biotecnología, E.T.S.I. Agrónomos, Universidad Politécnica de \\ Madrid, 28040 Madrid and $\ddagger$ Laboratorio de Biología Molecular y Virología Vegetal, C.I.T.-INIA, 28040 Madrid, Spain
}

\begin{abstract}
The chromosome complement of the grasshopper Dociostaurus genei is characterized by the presence of constitutive heterochromatin (C-bands) located in the centromeric regions of all the chromosomes and in the distal regions of some autosomes in the form of supernumerary segments. A sequence analysis was carried out to obtain information about the molecular characteristics of both heterochromatic regions. Two families of tandemly repetitive DNA (DgT2 and DgA3) from D. genei were cloned and characterized. Data obtained from in situ hybridization indicate that these families are located solely in the regions of constitutive heterochromatin. The DgT2 clone is representative of a family of sequences which mainly forms the centromeric C-bands in each chromosome of the complement. The DgA3 family is the major component of the distal C-bands (supernumerary segments) present in most of the autosomal pairs. These results show the existence in $D$. genei of two different families of repetitive DNA restricted to different chromosomal domains. We discuss these results in the light of the possible role of chromosomal disposition in the maintenance of the differences between heterochromatic DNA from different chromosomal regions and the homogenization of DNA sequences from equilocal chromosomal domains.
\end{abstract}

Keywords: constitutive heterochromatin, insect cytogenetics, satellite DNA.

\section{Introduction}

Eukaryotic genomes are characterized by the variable proportions of highly repetitive DNA families that they contain. These usually correspond to regions of constitutive heterochromatin that are revealed by C-banding (John, 1988). Other banding methods prove that these sequences are homogenized when they occupy identical chromosome distribution within a given complement (equilocality) and are different in distinct chromosome domains (heterogeneity) (King \& John, 1980; Greilhuber \& Loidl, 1983; Schweizer et al., 1983; Bella et al., 1986). Acridoid grasshoppers are a well-known example where constitutive heterochromatin is present in the

${ }^{*}$ Correspondence. form of prominent centromeric or distal blocks (Hewitt, 1979). However, much less is known about the molecular organization of these regions compared with other plant and animal species. There are a few examples where in situ hybridization has enabled the localization of particular families of highly repetitive DNA sequences in grasshoppers (Brown \& Wilmore, 1974; Arnold et al., 1986; John et al., 1986; López-León et al., 1994).

Dociostaurus genei is a grasshopper which displays a complex polymorphism of distal supernumerary segments (Rodríguez Iñigo et al., 1993) besides the characteristic pericentromeric C-bands present in every chromosome. We have shown that both kinds of heterochromatin differ not only in location but also in composition. Although both are AT rich, as revealed by DAPI staining, the centromeric hetero- 
chromatin is extensively in situ-digested by the endonucleases Sau3AI and TaqI, whereas the distal segments are mostly sensitive to AluI (Rodríguez Iñigo et al., 1993). These data prompted us to analyse the structure and the genome organization of the sequences included in both kinds of constitutive heterochromatin. The results also allow us to consider the role of chromosome disposition in the promotion of the homogeneity of sequences located in equilocal regions and the heterogeneity of sequences located in opposite chromosome domains.

\section{Material and methods}

Adult males and females of the grasshopper $D$. genei were collected from natural populations in the Central region of Spain. The chromosome complement is composed of 11 acrotelocentric autosome pairs and a single acrotelocentric sexual (X) chromosome in males. The sex chromosome system is of the $\mathrm{X} 0$ (males), $\mathrm{XX}$ (females) type.

\section{Cytological procedures}

Mitotic chromosomes were obtained from ovariole tips of females. These were injected intra-abdominally with 0.05 per cent colchicine in saline solution and left for 5 h. Fixation was carried out in 3:1 ethanol:acetic acid. To carry out cytological analysis, squash preparations were made in a drop of acetic acid 45 per cent. The coverslips were removed after freezing in liquid nitrogen and the slides were then air-dried.

C-banding was performed according to LópezFernández \& Gosálvez (1981).

\section{Isolation of genomic DNA}

To isolate genomic DNA, adult individuals were homogenized in WCLB (10 mM Tris- $\mathrm{HCl}, 10 \mathrm{~mm}$ $\mathrm{NaCl}, 20 \mathrm{~mm}$ EDTA), SDS 2 per cent and proteinase- $\mathrm{K}$, incubated at $37^{\circ} \mathrm{C}$ for $16 \mathrm{~h}$ and then placed on ice for $1 \mathrm{~h}$ after adding $\mathrm{NaCl}$ to a final concentration of $2 \mathrm{~m}$. The homogenate was then centrifuged at $2240 \mathrm{~g}$ for $15 \mathrm{~min}$. The resultant supernatant was extracted with 1 volume of phenol-chloroformisoamyl alcohol (25:24:1) and 1 volume of chloroform-isoamyl alcohol (24:1) and precipitated with 2 volumes of ethanol. The precipitated nucleic acid was finally washed with 70 per cent ethanol, air-dried, dissolved in TE (10 mm Tris/1 mM EDTA) $\mathrm{pH} 8$ at a concentration of $1 \mu \mathrm{g} \mu \mathrm{L}^{-1}$ and digested with RNAse $\left(0.1 \mu \mathrm{g} \mu \mathrm{L}^{-1}\right)$.

\section{DNA blot hybridization}

For Southern blotting, $10 \mu \mathrm{g}$ of total DNA was digested with the appropriate enzyme at $2 \mathrm{U} \mu \mathrm{g}^{-1}$ DNA for 2-8 h. The resulting fragments were fractionated on a 1.5 per cent agarose gel in $1 \times$ TAE buffer (Tris-acetate/EDTA) and transferred to Hybond $^{\mathrm{TM}+}$ nylon filters as recommended by the manufacturer. The DNA was fixed at $80^{\circ} \mathrm{C}$ for $2 \mathrm{~h}$.

Probes were amplified by PCR under standard conditions (Sambrook et al., 1989) and radiolabelled with ${ }^{32} \mathrm{P}$-dCTP by random priming (Feinberg \& Vogelstein, 1983). Filters were prehybridized for $2 \mathrm{~h}$ with $5 \times \mathrm{SSPE}, 5 \times$ Denhardt's solution, 0.5 per cent SDS and $100 \mu \mathrm{g} \mathrm{mL}^{-1}$ denatured salmon sperm DNA at hybridization temperature $\left(65^{\circ} \mathrm{C}\right)$. The radiolabelled denatured probe was added and hybridization performed at $65^{\circ} \mathrm{C}$ for $16 \mathrm{~h}$. The filters were washed twice in $2 \times \mathrm{SSPE}, 0.1$ per cent SDS; then once in $1 \times$ SSPE, 0.1 per cent SDS; and then once in $0.1 \times \mathrm{SSPE}, 0.1$ per cent SDS. All washes were performed for $15 \mathrm{~min}$ at $65^{\circ} \mathrm{C}$. Finally they were exposed to X-ray film at $-80^{\circ} \mathrm{C}$ for $1-25 \mathrm{~h}$.

\section{Cloning of repetitive DNA}

For molecular cloning digested total DNA from $D$. genei was fractionated on 1.5 per cent agarose gel in $1 \times$ TAE buffer under standard conditions (Sambrook et al., 1989). The bands of interest were excised and DNA was purified and ligated in the pBluescript $\mathrm{SK}^{-}$vector. The resulting ligations were used to transform competent cells of E. coli JM 103 $\mathrm{recA}^{-}$. Recombinant clones were selected using standard protocols (Sambrook et al., 1989). Minipreparations of DNA from eight of the recombinant colonies from each ligation were made following Sambrook et al. (1989).

\section{DNA sequencing}

Sequencing was performed by the chain termination method (Sanger et al., 1977) using the Automated Laser Fluorescent A.L.F. DNA sequencer (Pharmacia LKB Biotechnology).

\section{Fluorescence in situ hybridization (FISH)}

For in situ hybridization the probes were amplified by PCR, under standard conditions (Sambrook et al., 1989) and labelled with digoxigenin 11-dUTP by nick translation (Rigby et al., 1977) according to the manufacturer's instructions (Boehringer-Mann- 
heim). Slides were pretreated prior to FISH with RNAse and pepsin according to Wiegant et al. (1991). In situ procedures were carried out following Pendás et al. (1993) with minor modifications. The preparations were denatured in 70 per cent formamide in $2 \times \mathrm{SSC}$ at $90^{\circ} \mathrm{C}$ for $5 \mathrm{~min}$ and dehydrated in ethanol series. Next $15 \mu \mathrm{L}$ of hybridization mixture consisting of 50 per cent $(\mathrm{v} / \mathrm{v})$ deionised formamide$2 \times \mathrm{SSC}, 10$ per cent $(\mathrm{w} / \mathrm{v})$ dextran sulphate, $50 \mathrm{~mm}$ phosphate buffer, $100 \mu \mathrm{g} \mathrm{mL}^{-1}$ of salmon sperm DNA, yeast t-RNA and $10 \mathrm{ng} \mu \mathrm{L}^{-1}$ of denatured labelled probe were placed on each slide, sealed with rubber solution and chromosomes and probe were denatured again together at $90^{\circ} \mathrm{C}$ for $10 \mathrm{~min}$. Slides were incubated at $37^{\circ} \mathrm{C}$ for $16 \mathrm{~h}$. After hybridization, slides were washed and the digoxigeninlabelled probes detected with fluorescein isothiocyanate conjugate (FITC). Depending on the degree of hybridization we used one (antidigoFITC), two (antidigo mouse: antimouse-FITC) or three (antidigo mouse: antimouse digo: antidigoFITC) antibodies. Chromosomes were counterstained with propidium iodide.

\section{Results}

\section{Sequence analysis}

After digesting the genomic DNA of D. genei with AluI, or TaqI endonucleases, monomeric bands of about $190 \mathrm{bp}$ were purified from 1.5 per cent agarose gels stained with ethidium bromide. These DNA bands were ligated, respectively, to the SmaI and $\mathrm{ClaI}$ sites of the pBluescript $\mathrm{SK}^{-}$vector. Recombinant clones were screened again to test the presence of repetitive DNA by hybridization with undigested DNA of D. genei. Clones with stronger signals (data not shown) were selected for subsequent sequence analysis (Fig. 1). The $\operatorname{Dg} A, 3$ sequence (Fig. 1a), cloned from the AluI band, is 160 nucleotides long and consists of 58.3 per cent AT. The DgT2 clone (from the TaqI band) is $217 \mathrm{bp}$ long and contains 59.2 per cent AT (Fig. 1b). No significant internal repeats have been observed in either sequence. A computerized comparison revealed no similarities between the two sequences. Moreover, none of the sequences showed significant homology with those in the EMBL Data Library.

The genome organization of these two sequences was analysed by DNA blot hybridization with digestions of $D$. genei DNA. These results, which are summarized in Fig. 2, show clear differences between the DgA3 and DgT2 genomic organization. The former shows the typical ladder pattern in the digestions of some enzymes which is indicative of a tandemly arranged repetitive DNA family (Fig. 2a). The results are in accordance with the restriction map obtained for the DgA3 sequence (Fig. 1a) such that AluI, PvuII (its target contains AluI's target) and Sau3AI, which have one recognition site in the cloned element, cleave within almost all the repeats. This results in a monomeric unit of approximately $204 \mathrm{bp}$ and the respective dimers and trimers. Digestions of DNA with enzymes that lacked cleavage sites in DgA3 yield instead two distinct patterns of hybridization: in treatments with EcoRI and DraI, the majority of homologous DNA remains undigested. On the other hand, TaqI digestion displays a series of bands ranging from about $670 \mathrm{bp}$ to undigested DNA.

DNA blot hybridization using DgT2 as a probe (Fig. 2b) shows a pattern of fragments that are in agreement with the restriction map obtained from the DgT2 sequence (Fig. 1b). Despite the fact that DgT2 lacks the DraI target, other clones obtained from DNA digestions with TaqI do contain it (data not shown). This would explain the band obtained when the DgT2 clone is hybridized with DraI digestions. Furthermore, DgT2 shows doublets in the TaqI lane separated by about $50 \mathrm{bp}$ and is thus in accordance with its restriction map (Fig. 1b). Treatments with REs that lacked cleavage sites in pDg T2 (EcoRI, AluI, PvuII) yielded hybridization signals in regions of high molecular weight. However, Sau3AI digests show an intense hybridization band (289 bp) despite not possessing the Sau3AI target.

The differences found in nucleotide sequence and genomic organization between the two clones and their possible relation with different heterochromatic regions was tested by in situ hybridization.

\section{In situ hybridization (F/SH)}

Probes from the $\mathrm{DgA} 3$ and $\mathrm{DgT} 2$ clones were labelled and hybridized to mitotic chromosomes of $D$. genei. The DgT2 sequence is localized in the centromere region of each chromosome where constitutive heterochromatin is sited (Fig. 3b). The size of the hybridization fits well with the size of the corresponding C-bands and is similar in size among the distinct members of the complement (compare Figs $3 a$ and $b$ ). These results suggest that this sequence is a representative of the family which mainly forms those regions of constitutive heteroch romatin.

The DgA3, in turn, hybridizes with the distal regions of some autosomes (Fig. 3c). In this case there are visible differences in the size of the hybrid-

(C) The Genetical Society of Great Britain, Heredity, 76, 70-76. 
(a)

$\frac{A l u \mathrm{I}}{\text { AGCTGCCTGTATTCAGAACAGCAAGTGGATCACTGTGCATACCTCTGGAA }}$

ACGCAATTTGACGTGAAATATCAATTATAATTGTAGTTCCTCGTCCATAC

AACGCAGTTTATGGTGCTTTTTACACGGCTGGGCCAAATATGCAGAAAAT

$\frac{A l u I}{\text { TCAAGCAGCT }}$

(b)

\author{
TaqI \\ TCGAAATGCAAATAACGGCTTAACCGTTCATACGAGACGAAAATAGATTA
}

CCCAGACTTGTAGAGGAGAAAGTTCTCTACAACTTTGCTCTCTTATGTTT

TTTCGGAATCTCGCACCGTTTCAGAGATATTTGTAAAAATATCGGAGATT

$\frac{\text { TaqI }}{\text { TGACGACGCGTGTCTGTCGATAGACAATCCGGTTTCGGAAACACTACGTT }}$

\title{
CCAATGTGCAGTTTCGA
}

Fig. 1 Nucleotide sequences of two clones obtained from (a) AluI and (b) TaqI digestions of the genomic DNA of Dociostaurus genei. Relevant targets of restriction endonucleases are marked. EMBL accession numbers: DgA3: X83723; DgT2: X83724.

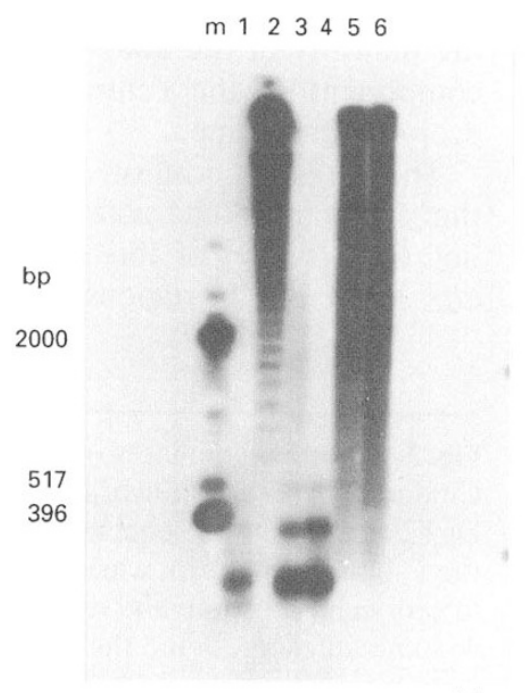

(a)

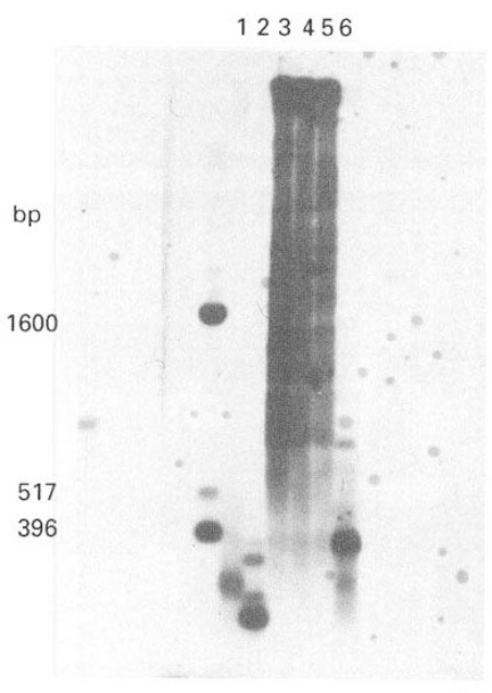

(b)

Fig. 2 Southern hybridization of probes from (a) DgA3 and (b) DgT2 clones. Marker (m); Sau3AI (1); TaqI (2); AluI (3); PvuII (4); EcoRI (5); DraI (6). Note in (a) the typical hybridization pattern of monomers, dimers and trimers with $A l u$ I (3) and PvuII (4) digestions and in (b) the doublet hybridization bands obtained with TaqI (2) digestion.

(c) The Genetical Society of Great Britain, Heredity, 76, 70-76. 

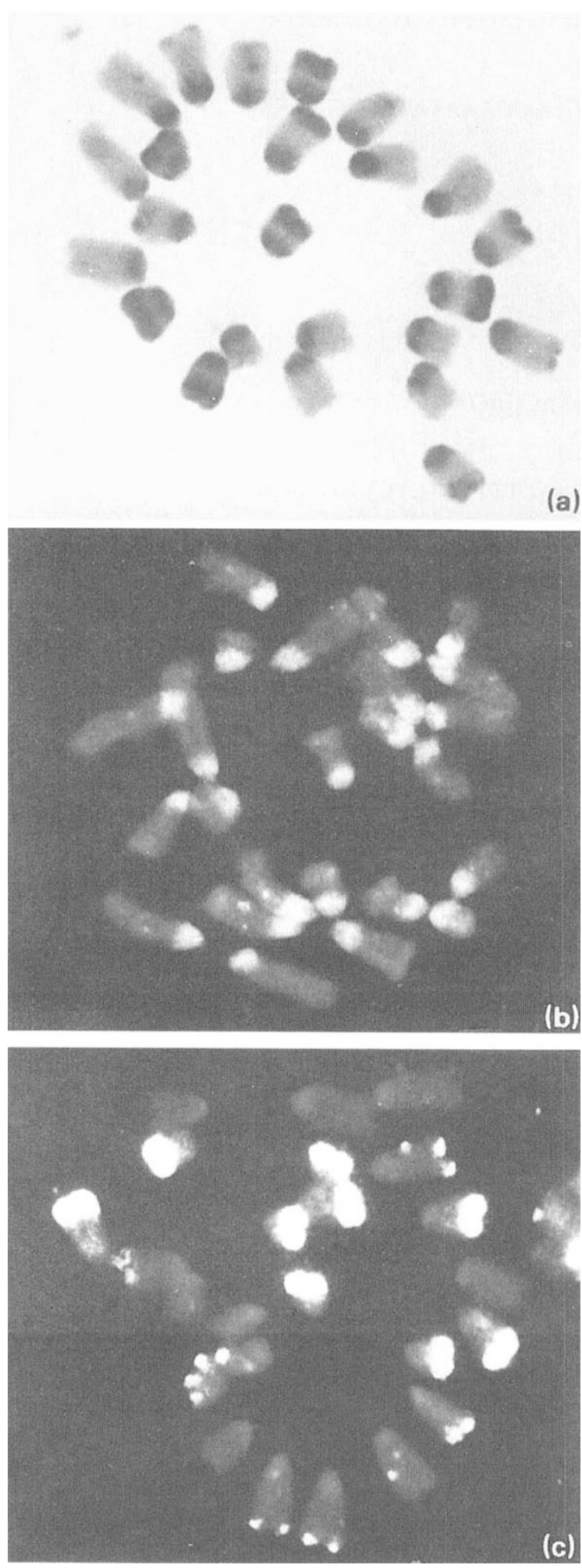

ization signals depending on the chromosome. These observations agree with the differences in size which characterize the distal supernumerary heterochromatic segments present in the majority of the autosomes of this species. The small chromosomes which commonly have large segments show prominent hybridization signals, while medium-sized chromosomes which have smaller segments display smaller signals (compare Figs $3 \mathrm{a}$ and $\mathrm{c}$ ). Moreover, this correspondence also affects those cases where the segment is present in only one of the homologues. Interestingly, hybridization of this probe in the distal tips of some of the longer autosomes is also visible although these chromosomes do not show prominent $\mathrm{C}$-bands in that region. These results clearly indicate that the $\mathrm{DgA} 3$ probe is a representative of the family of the highly repetitive DNA family which is the major component of the supernumerary segments.

Moreover, the analysis of the hybridization in telophase nuclei also shows the different location of both sequences and the Rabl polarization of the chromosomes (Fig. 4).

\section{Discussion}

The sequence analysis of representatives of repeated DNA families in $D$. genei has allowed the characterization of two of them. The in situ localization of probes from these sequences has confirmed that they must represent distinct families. Particularly, they occupy two distinct chromosome domains of constitutive heterochromatin: $\mathrm{DgA} 3$ is the major constituent of the distal supernumerary segments of the majority of the autosomes, and DgT2 is a major component of the centromeric heterochromatin of every chromosome.

These results confirm previous analyses based on the cytogenetic characterization of the constitutive heterochromatin of this species (Rodríguez Iñigo et al., 1993). Both regions show bright fluorescence

Fig. 3 Mitotic metaphases of Dociostaurus genei after (a) C-banding, and in situ hybridization of probes from (b) DgT2 and (c) DgA3 sequences. The comparison between the C-banding pattern, which includes centromeric bands in every chromosome and distal supernumerary segments in some autosomes, and the localization of each hybridization reveals the correspondence of a particular sequence with a distinct heterochromatic chromosome domain. The DgT2 probe hybridizes with the centromere regions whereas the $\mathrm{DgA} 3$ probe is located exclusively in the distal regions of some autosomes. 

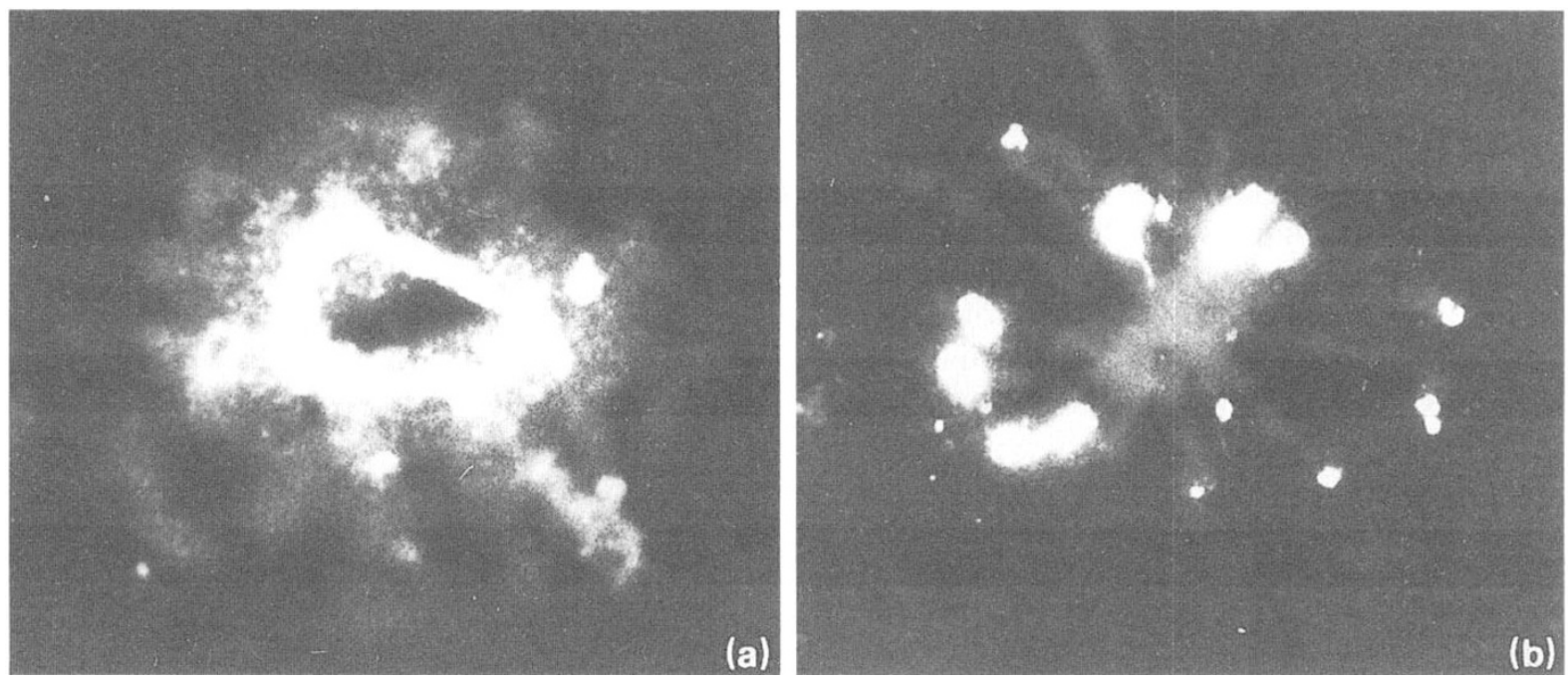

Fig. 4 Mitotic telophase nuclei of Dociostaurus genei after in situ hybridization of (a) DgT2 and (b) pDg A3 probes. Note the Rabl polarization in both cases.

with DAPI staining which indicates AT richness. This correlates with the percentages of AT of both sequences (58.3 per cent in DgA3 and 59.2 per cent in DgT2). Moreover, the endonucleases which intensively digest a particular kind of constitutive heterochromatin region in fixed chromosomes yield restriction patterns of repetitive sequences in gels. Thus, the chromosome regions occupied by the centromeric heterochromatin and the supernumerary segments are digested by $T a q \mathrm{I}$ and $A l u \mathrm{I}$ endonucleases, respectively (Rodríguez Iñigo et al., 1993), and the sequences (DgT2 and DgA3) come from prominent bands of DNA digestions with these same enzymes (Fig. 1).

These sequences are sequestered in two distinct and compartmentalized chromosome domains of constitutive heterochromatin. This chromosome location concords with two properties defined for the heterochromatin in other organisms: heterogeneity and equilocality (John, 1988).

Thus, a particular chromosome domain (centromere region and distal supernumerary segments in the case of $D$. genei) shows homogeneous composition among the members of the chromosome complement. On the other hand, the composition of both kinds of heterochromatic regions is clearly different. Moreover, as they represent two distinct families of repetitive DNA, the origin and evolution of these sequences agree with models based on the spatial organization of chromosomes in the nuclei (Schweizer \& Loidl, 1987; Schweizer et al., 1987). The Rabl polarization which predicts the colocalization of the centromeres throughout the mitotic cycle is a powerful model by which the heterochromatin transfer between homologous and nonhomologous chromosomes may occur (see Fig. 4). In the same way, the proximity of heterochromatic DNA in the early meiosis ('bouquet polarization') may provide a cytological basis for the molecular processes which are responsible for the maintenance of satellite DNA sequence homogeneity between equilocal groups of C-bands on both homologous and nonhomologous chromosomes.

The distal regions of acrotelocentric chromosomes would occupy the opposite domain to that of the centromeres within nuclei (Fig. 4). The differences in size of the distal blocks present in most of the autosomes of $D$. genei may also reflect the origin and evolution of this component of the constitutive heterochromatin. Schweizer \& Loidl (1987) suggested that the heterochromatin transfer between equilocal regions of a complement should occur between nonhomologues of similar size. In $D$. genei it is reasonable to suppose that this process would have originated in the smaller members of the complement, and then in a sequential fashion the supernumerary material would invade increasingly longer chromosomes. Thus one finds at present that the supernumerary segments are bigger in the shorter chromosomes and decrease in size in longer chromosomes. In fact, in situ hybridization shows that the sequence representative of these segments is also present in the longest chromosome pairs where no supernumerary segments or prominent C-bands are detected (compare Figs $3 \mathrm{a}$ and c).

Supernumerary heterochromatic segments have 
been defined in terms of a portion of heterochromatin which is amplified and that is clearly dispensable as the organism can develop normally in its absence (John, 1983). Thus the supernumerary segments of $D$. genei are a tenable example of sequences that originate and accumulate by an efficient mechanism of amplification. The 'infective process' has reached most of the autosomes and, as supposed for parasitic DNA sequences, seems to elude the selective forces against its incorporation and maintenance.

\section{Acknowledgements}

We are indebted for help and advice to Drs J. Orellana, J. Salinas and J. M. M. Zapater. We also thank Drs J. Gosálvez and P. L. Mason for kindly reviewing the manuscript. This work was supported by grants PB 90-0192 and AGF 93-0869 awarded by the Comisión Interministerial Científica y Técnica (Spain).

\section{References}

ARNOLD, M. L., APPELS, R. AND SHAw, D. D. 1986. The heterochromatin of grasshoppers from the Caledia captiva species complex. I. Sequence evolution and conservation in a highly repeated DNA family. $\mathrm{Mol}$. Biol. Evol., 3, 29-43.

BElla, J. L., GARCía de la VEGA, C., LÓPEZ-FERnÁNDEZ, C. AND GosÁlvez, J. 1986. Changes in acridine orange binding and its use in the characterisation of heterochromatic regions. Heredity, 57, 79-83.

BROWN, A. K. AND WILMORE, P. J. 1974. Location of repetitious DNA in the chromosomes of the desert locust (Schistocerca gregaria). Chromosoma, 47, 379-383.

FEINBERG, A. P. AND VOGELSTEIN, B. 1983. A technique for radiolabelling DNA restriction endonuclease fragments to high specific activity. Analyt. Biochem., 132, 6-13.

GREILHUBER, J. AND LOIDL, J. 1983. On regularities of C-banding patterns and their possible cause. In: Brandham, P. E. and Bennett, M. D. (eds) Kew Chromosome Conference II, p. 344. George Allen and Unwin, London.

HewitT, G. M. 1979. Orthoptera. Animal Cytogenetics 3, Insecta 1. Gebrüder Borntraeger, Stuttgart.

JoHN, B. 1983. The role of chromosome change in the evolution of orthopteroid insects. In: Sharma, A. K. and Sharma, A. (eds) Chromosomes in Evolution of Eukaryotic Groups, vol. 1, pp. 1-110. CRC Press, Boca Raton, FL.
JOHN, B. 1988. The biology of heterochromatin. In: Verma, R. S. (ed.) Heterochromatin, pp. 1-147. Cambridge University Press, Cambridge.

JOHN, B., APPELS, R. AND CONTRERAS, N. 1986. Population cytogenetics of Atractomorpha similis. II. Molecular characterization of the distal C-band polymorphisms. Chromosoma, 94, 45-58.

KING, M. AND JOHN, B. 1980. Regularities and restrictions governing $\mathrm{C}$-band variation in acridoid grasshoppers. Chromosoma, 76, 123-150.

LÓPEZ-FERNÁNDEZ, C. AND GOSÁlvEZ, J. 1981. Differential staining of a heterochromatic zone in Arcyptera fusca (Orthoptera). Experientia, 37, 240.

LÓPEZ-LEÓN, M.D., NEVES, N., SCHWARZACHER, T., HESLOPHARRISON, J. S. (PAT), HEWITT, G. M. AND CAMACHO, J. P. M. 1994. Possible origin of a B chromosome deduced from its DNA composition using double FISH technique. Chromosome Res., 2, 87-92.

PENDAS, A. M., MORAN, P. AND GARCIA-VAZQueZ, E. 1993. Ribosomal RNA genes are interspersed throughout a heterochromatic arm in Atlantic salmon. Cytogenet. Cell Genet., 63, 128-130.

RIGBY, P. W. Z., DIECKMANN, M., RHODES, C. AND BERG, P. 1977. Labelling deoxyribonucleic acid to high specific activity in vitro by nick traslation with DNA polymerase. J. Mol. Biol., 113, 237-251.

RODRÍGUEZ INIIGO, E., BELLA, J. L. AND GARCÍA DE LA VEGA, C. 1993. Heterochromatin differentiation between two species of the genus Dociostaurus (Orthoptera: Acrididae). Heredity, 70, 458-465.

SAMBROOK, J., FRITSCH, E. F. AND MANIATIS, T. 1989. Molecular Cloning. A Laboratory Manual, 2nd edn. Cold Spring Harbor Laboratory Press, New York.

SANGER, F., NICKLEN, S. AND COUlSON, A. R. 1977. DNA sequencing with chain-terminating inhibitors. Proc. Natl. Acad. Sci. U.S.A., 74, 5463-5467.

SCHWEIZER, D. AND LOIDL, J. 1987. A model for heterochromatin dispersion and the evolution of $\mathrm{C}$ band patterns. In: Stahl, A., Luciani, J. M. and Vagner-Capodano, A. M. (eds) Chromosomes Today, vol. 9, pp. 61-74. Allen \& Unwin, London.

SCHWEIZER, D., MENDELAK, M., WHITE, M. J. D. AND CONTRERAs, N. 1983. Cytogenetics of the parthenogenetic grasshopper Warramaba virgo and its bisexual relatives. X. Patterns of fluorescent banding. Chromosoma, 88, 227-236.

SCHWE1ZER, D., LOIDL, J. AND HAMILTon, B. 1987. Heterochromatin and the phenomenon of chromosome banding. In: Hennig, W. (ed) Structure and Function of Eukaryotic Chromosomes, pp. 235-254. Springer, Berlin. WIEGANT, J., NEDERIOF, P. M., VAN DER PlOEG, M., TANLE, H. J. AND RAAP, A. K. 1991. In situ hybridization with fluoresceinated DNA. Nucl. Acids Res., 19, 3277-3241. 